\title{
Diagnosing an atypical site of giant cell arteritis with magnetic resonance angiography: a case report
}

\author{
Boon L. Tan', Jonathan J. Liư ${ }^{4}$, Tuck Y. Yong ${ }^{2}$, Chrismin C. Tan ${ }^{3}$ and Jordan Y. Li $i^{1,4^{*}}$
}

\begin{abstract}
Background: Giant cell arteritis typically involves the temporal arteries, but can involve other cranial arteries. Temporal artery biopsy is the mainstay for the diagnosis of giant cell arteritis; however, biopsy may be problematic if giant cell arteritis involves other cranial arteries that are inaccessible for sampling. In these situations, magnetic resonance angiography is a useful, non-invasive adjunctive method in the diagnosis of giant cell arteritis. In this case report, we describe a case of giant cell arteritis involving only the occipital artery which was revealed by magnetic resonance angiography.

Case presentation: A 67-year-old Caucasian man was admitted to our hospital with a 4-week history of malaise, fever, and mild occipital headaches. There were no other positive findings on physical examination. Laboratory studies were remarkable for normocytic anemia, raised inflammatory markers, and mildly deranged liver function tests. To exclude intracranial pathology, he underwent a cranial magnetic resonance imaging with gadolinium, which demonstrated a thickened wall and mural enhancement of his right occipital artery, consistent with giant cell arteritis. His temporal arteries were normal. His occipital arteries were not accessible for biopsy and he was commenced on high-dose prednisolone (60 mg daily). His symptoms resolved completely after a week of glucocorticoid steroid treatment and he was well on $5 \mathrm{mg}$ of prednisolone once a day on follow-up.
\end{abstract}

Conclusion: While magnetic resonance angiography may not replace the need for biopsy, it may have a diagnostic role in suspected giant cell arteritis, such as when the involved arteries are inaccessible for biopsy.

Keywords: Extracranial involvement, Giant cell arteritis, Magnetic resonance angiography, Vasculitis

\section{Background}

Giant cell arteritis (GCA) is a chronic inflammatory disorder characterized by granulomatous infiltrates affecting the large and medium-sized vessels. It is closely related to polymyalgia rheumatica (PMR) [1]. GCA occurs predominantly in females, with a mean age at diagnosis of 72 years [2] and is the most common chronic vasculitis of medium and large arteries in populations with predominantly Northern European ancestry. The diagnostic criteria for GCA according to American College of Rheumatology $(\mathrm{ACR})$, require the fulfilment of at least three of the

\footnotetext{
* Correspondence: jordan.li@sa.gov.au

'Department of General Medicine, Flinders Medical Centre, Flinders Drive, Bedford Park, South Australia 5042, Australia

${ }^{4}$ School of Medicine, Flinders University, Bedford Park, South Australia, Australia

Full list of author information is available at the end of the article
}

following five criteria: (i) age more than 50 years, (ii) new headache, (iii) superficial temporal artery tenderness or decreased pulsation, (iv) elevated erythrocyte sedimentation rate (ESR) of more than $50 \mathrm{~mm} /$ hour using the Westergren method, and (v) abnormal findings on temporal artery biopsy [3]. GCA can be a diagnostic challenge for physicians due to the wide variation of presentations, false negative histology, absence of potential biopsy sites, or lack of cranial symptoms. Furthermore, cranial arteries other than the temporal artery are involved in more than half of GCA cases [1]. As a result, symptoms are often atypical and may include fever, general malaise and weight loss. We report a case of GCA with only right occipital artery involvement diagnosed by magnetic resonance angiography (MRA). 


\section{Case presentation}

A 67-year-old Caucasian man presented with a 4-week history of general malaise, mild occipital headache, and fever. He has a past medical history of hypercholesterolemia and a stable right acoustic neuroma under observation. He described no visual disturbance, jaw claudication, arthralgia, or weight loss.

On physical examination, he was febrile with temperature of $38{ }^{\circ} \mathrm{C}$. He had no active synovitis or rash. His temporal arteries were not palpable; a cranial nerve and funduscopic examination was normal. There was no lymphadenopathy or hepatosplenomegaly. The rest of the physical examination was unremarkable.

Laboratory investigations showed mild normocytic anemia, raised inflammatory markers, and mild deranged liver function test (Table 1). Renal function and electrolytes were within normal reference ranges. Multiple blood and urine cultures were negative. Further investigations including vasculitic screen, complete autoimmune screen, infective viral screen, and malignant screen were either

Table 1 Laboratory, serological, and immunological investigation results

\begin{tabular}{lll}
\hline Variables & Results & $\begin{array}{l}\text { Normal reference } \\
\text { range }\end{array}$ \\
\hline Hemoglobin & $116 \mathrm{~g} / \mathrm{L}$ & $135-175 \mathrm{~g} / \mathrm{L}$ \\
Red blood cells & $3.95 \times 10^{12} \mathrm{~L}$ & $\begin{array}{l}4.50-6.00 \times 10^{12} \mathrm{~L} \\
80.0-98.0 \mathrm{fl}\end{array}$ \\
Mean cell volume & $91.6 \mathrm{fl}$ & $150-450 \times 10^{9} \mathrm{~L}$ \\
Platelet count & $484 \times 10^{9} / \mathrm{L}$ & $4.00-11.0 \times 10^{9} / \mathrm{L}$ \\
White cell count & $6.61 \times 10^{9} / \mathrm{L}$ & $1.80-7.50 \times 10^{9} / \mathrm{L}$ \\
Neutrophils & $4.83 \times 10^{9} / \mathrm{L}$ & $<60 \mathrm{U} / \mathrm{L}$ \\
Gamma-glutamyl transpeptidase & $189 \mathrm{U} / \mathrm{L}$ & $30-110 \mathrm{U} / \mathrm{L}$ \\
Alkaline phosphatase & $172 \mathrm{U} / \mathrm{L}$ & $<55 \mathrm{U} / \mathrm{L}$ \\
Alanine aminotransferase & $165 \mathrm{U} / \mathrm{L}$ & $<45 \mathrm{U} / \mathrm{L}$ \\
Aspartate aminotransferase & $65 \mathrm{U} / \mathrm{L}$ & $110-230 \mathrm{U} / \mathrm{L}$ \\
Lactate dehydrogenase & $167 \mathrm{U} / \mathrm{L}$ & $137-145 \mathrm{mmol} / \mathrm{L}$ \\
Sodium & $139 \mathrm{mmol} / \mathrm{L}$ & $3.5-4.9 \mathrm{mmol} / \mathrm{L}$ \\
Potassium & $4.2 \mathrm{mmol} / \mathrm{L}$ \\
Urea & $4.0 \mathrm{mmol} / \mathrm{L}$ & $2.7-8.0 \mathrm{mmol} / \mathrm{L}$ \\
Creatinine & $53 \mu \mathrm{mol} / \mathrm{L}$ & $50-120 \mathrm{Mmol} / \mathrm{L}$ \\
Erythrocyte sedimentation rate (ESR) & $96 \mathrm{~mm} / \mathrm{h}$ & $1-13 \mathrm{~mm} / \mathrm{h}$ \\
C-reactive protein (CRP) & $400 \mathrm{mg} / \mathrm{L}$ & $<10 \mathrm{mg} / \mathrm{L}$ \\
Antinuclear antibody & Negative & \\
Extractable nuclear antibody & Negative & \\
Anti-neutrophil cytoplasmic & Negative & \\
Hepatitis B and C serology & Negative \\
Liver, kidney mitochondrial antibody & Negative \\
Smooth muscle antibody & Negative \\
Anti-mitochondrial antibody & Negative \\
Serum electrophoresis & No paraprotein \\
\hline
\end{tabular}

negative or in the normal range (Table 1). Computed tomography $(\mathrm{CT})$ of his neck, thorax, abdomen and pelvis were negative for lymphadenopathy, mass, abscess, and infective focus. A bone morrow biopsy and aspirate showed mild reactive plasmacytosis and the culture was negative for tuberculosis.

In the setting of fever, headache, and raised inflammatory markers, our patient underwent a cranial 3.0 tesla (3T) magnetic resonance imaging (MRI) with gadolinium, which showed a thickened wall and mural enhancement of his right occipital artery consistent with GCA (Fig. 1). His temporal arteries were normal bilaterally. After consultation with vascular surgeons, there was no potential biopsy site to enable histopathological confirmation. A diagnosis of GCA was considered and he was started on oral prednisolone (60 $\mathrm{mg}$ daily). He became afebrile on the second day of treatment and all symptoms resolved within 1 week. On follow-up, he has been well and the prednisolone dose has been gradually tapered down to $5 \mathrm{mg}$ daily. Six weeks after the glucocorticoid steroid treatment, he underwent an 18flurodeoxyglucose $\left({ }^{18} \mathrm{FDG}\right)$ positron emission tomography (PET) scan, which revealed complete resolution of occipital GCA and no evidence of other vasculitis.

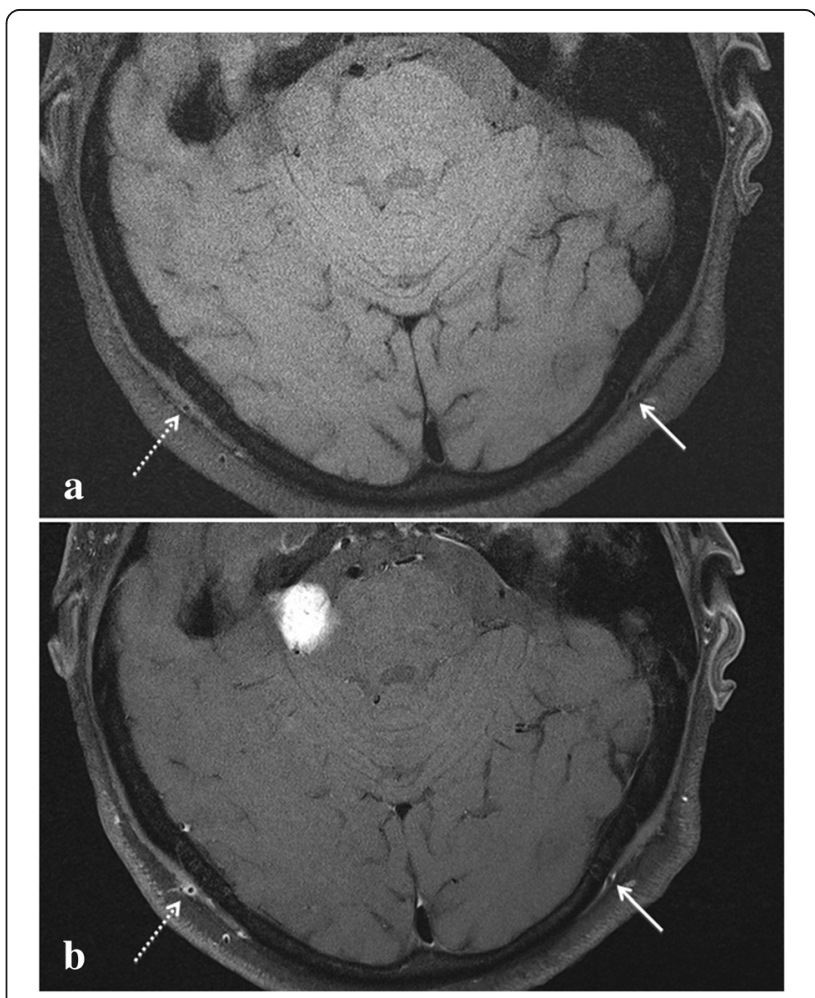

Fig. 1 High-resolution $T 1$ fat-saturated magnetic resonance sequences before (a) and after (b) intravenous gadolinium injection demonstrates mural thickening and enhancement in the right occipital artery (dashed arrow). Solid arrow denotes the less-affected left occipital artery 


\section{Discussion}

Other cranial arteries can be involved in GCA apart from the temporal arteries [4]. Branches of the external carotid artery, including the posterior ciliary arteries that supply the optic nerve and primary and secondary branches of the aorta are often affected. GCA of the lower extremity arteries and mesenteric arteries is extremely rare, while intracranial arteries are essentially spared [5]. The diagnosis of GCA is usually confirmed by temporal artery biopsy with histopathology demonstrating panarteritis with mononuclear infiltrates penetrating all layers of the arterial wall [1]. However, this can pose a problem in cases where the temporal artery is spared. Furthermore, the inflammation of the temporal artery in GCA can be segmental making the diagnosis of GCA challenging even when the affected artery is accessible for biopsy. An estimate of the actual sensitivity of unilateral temporal artery biopsy is between 69 and $95 \%$ [6]. As a result, there is a growing interest in using radiological imaging in the investigation of patients with suspected GCA [7].

High resolution MRI with gadolinium is a useful noninvasive adjunctive method in diagnosis of GCA. Highresolution MRI in particular allows detailed assessment of the major superficial cranial arteries, and administration of gadolinium allowing detection of arterial wall thickening and periadventitial enhancement suggestive of mural inflammation. These abnormalities are likely to represent the early vascular inflammation that precedes the development of luminal changes and can be used as a guide to estimating disease activity [8]. Single-center and multi-center trials evaluating MRI of the superficial cranial arteries (superficial temporal and occipital arteries) have yielded an overall sensitivity of between 78 and $89 \%$ and specificity between 90 and $92 \%$ for the diagnosis of GCA [7, 9]. A further role for MRI in following up of GCA response to treatment and monitoring for recurrent disease activity has also been proposed [10].

One case report and a small study have suggested that high resolution contrast-enhanced, black-blood T1weighted images with fat suppression might be useful for the diagnosis of intracranial arteritis $[11,12]$. This may allow invasive procedures to be replaced, such as conventional angiography and/or brain biopsies. However, the role of black-blood T1-weighted images in diagnosing extracranial arteritis has not been evaluated. Further studies are needed to confirm these initial promising results.

Conventional angiography and CT angiography can also document large vessel involvement in GCA [13], although the risks associated with radiation exposure and iodinated contrast media may limit scanning in patients who are allergic to contrast or have renal impairment. Sonographic features such as a hypoechoic periluminal halo have been shown to have a high specificity for GCA on meta-analysis, but its sensitivity and specificity values have not been compared directly with MRI [14, 15]. More advanced disease may be seen sonographically as vascular stenosis or occlusion. Recent literature identifies ${ }^{18}$ FDG PET scans as well suited for the demonstration of GCA in arteries exceeding $4 \mathrm{~mm}$ in diameter [16]. While not currently felt suitable to replace the need for biopsy, a potential role has been suggested for MRA or ${ }^{18}$ FDG PET scan in the diagnosis of atypical GCA, where conventional clinical features and temporal artery biopsy are non-contributory, or for follow-up after corticosteroid therapy.

\section{Conclusions}

In summary, atypical cases of GCA such as that presented here pose a diagnostic dilemma to the clinician due to the variable and nonspecific nature of patient presentation. Although clinical features may be suggestive, inability to obtain histopathological confirmation can limit diagnostic certainty. The increasing sensitivity and specificity of high-resolution MRI not only allows more confident diagnosis of these atypical cases but may even play a role in monitoring for response to treatment or recurrent disease.

\section{Acknowledgement}

No funds were received in support of this study.

\section{Authors' contributions}

$B T, J L$, and TY analyzed the patient data and wrote the case. $C T$ provided the images. JYL reviewed and revised the manuscript. All authors read and approved the final manuscript.

\section{Authors' information}

Jonathan J. Liu, Year 4 medical student.

\section{Competing interests}

The authors declare that they have no competing interests.

\section{Consent for publication}

Written informed consent was obtained from the patient for publication of this case report and accompanying images. A copy of the written consent is available for review by the Editor-in-Chief of this journal.

\section{Author details}

'Department of General Medicine, Flinders Medical Centre, Flinders Drive, Bedford Park, South Australia 5042, Australia. ${ }^{2}$ Flinders Private Hospital, Flinders Dr, Bedford Park, SA 5042, Australia. ${ }^{3}$ Department of Medical Imaging, Flinders Medical Centre, Flinders Drive, Bedford Park, South Australia 5042, Australia. ${ }^{4}$ School of Medicine, Flinders University, Bedford Park, South Australia, Australia.

Received: 31 October 2015 Accepted: 3 June 2016

Published online: 23 June 2016

References

1. Salvarani C, Cantini F, Hunder GG. Polymyalgia rheumatica and giant-cell arteritis. Lancet. 2008:372:234-45.

2. Smetana GW, Shmerling RH. Does this patient have temporal arteritis? JAMA. 2002;287:92-101.

3. Hunder GG, Block DA, Michael BA, et al. The American College of Rheumatology 1990 criteria for the classification of giant cell arteritis. Arthritis Rheum. 1990;33:1122-8. 
4. Pfadenhauer K, Weber H. Duplex sonography of the temporal and occipital artery in the diagnosis of temporal arteritis. A prospective study. J Rheumatol. 2003;30:2177-81.

5. Brack A, Martinez-Taboada V, Stanson A, et al. Disease pattern in cranial and large-vessel giant cell arteritis. Arthritis Rheum. 1999;42:311-7.

6. Niederkohr RD, Levin LA. A Bayesian analysis of the true sensitivity of a temporal artery biopsy. Invest Opthalmol Vis Sci. 2007;48(2):675-80.

7. Klink T, Geiger J, Both M, et al. Giant cell arteritis: Diagnostic accuracy of MR imaging of superficial cranial arteries in initial diagnosis - results of a multicenter trial. Radiology. 2014;273(3):844-52.

8. Narvaez J, Narvaez JA, Nolla JM, et al. Giant cell arteritis and polymyalgia rheumatica: usefulness of vascular magnetic resonance imaging studies in the diagnosis of aortitis. Rheumatology (Oxford). 2005;44:479-83.

9. Bley TA, Weiben $\mathrm{O}$, Uhl M, et al. Assessment of the cranial involvement pattern of giant cell arteritis with $3 \mathrm{~T}$ magnetic resonance imaging. Arthritis Rheum. 2005;52:2470-7.

10. Bley TA, Markl M, Schelp M, et al. Mural inflammatory hyperenhancement in MRI of giant cell (temporal) arteritis resolves under corticosteroid treatment. Rheumatology (Oxford). 2008:47:65-7.

11. Pfefferkorn T, Linn J, Habs M, et al. Black blood MRI in suspected large artery primary angiitis of the central nervous system. J Neuroimaging. 2013:23:379-83.

12. Saam T, Habs M, Pollatos $\mathrm{O}$, et al. High-resolution black-blood contrast-enhanced $\mathrm{T} 1$ weighted images for the diagnosis and follow-up of intracranial arteritis. Br J Radiol. 2010;83:e182-4.

13. Stanson AW. Imaging findings in extracranial (giant cell) temporal arteritis. Clin Exp Rheumatol. 2000;18:543-8.

14. Karassa FB, Matsagas MI, Schmidt WA, et al. Meta-analysis: test performance of ultrasonography for giant-cell arteritis. Ann Intern Med. 2005;142:359-69.

15. Schmidt WA, Natusch A, Moller DE, et al. Involvement of peripheral arteries in giant cell arteritis: a color Doppler sonography study. Clin Exp Rheumatol. 2002;20:309-18.

16. Brodmann $M$, Lipp RW, Passath $A$, et al. The role of $2-{ }^{18}$-flluoro-2-deoxy-D-glucose positron emission tomography in the diagnosis of giant cell arteritis of the temporal arteries. Rheumatology (Oxford). 2004;43:241-2.

\section{Submit your next manuscript to BioMed Central and we will help you at every step:}

- We accept pre-submission inquiries

- Our selector tool helps you to find the most relevant journal

- We provide round the clock customer support

- Convenient online submission

- Thorough peer review

- Inclusion in PubMed and all major indexing services

- Maximum visibility for your research

Submit your manuscript at www.biomedcentral.com/submit

) Biomed Central 